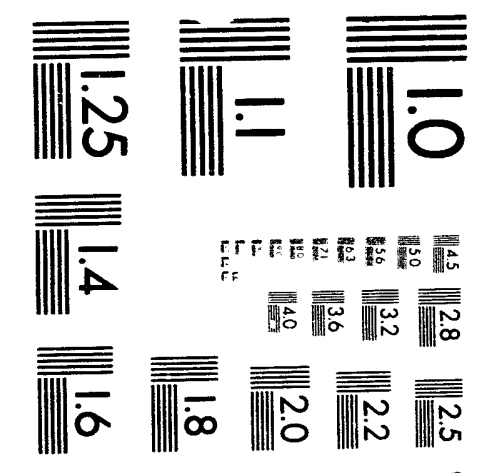



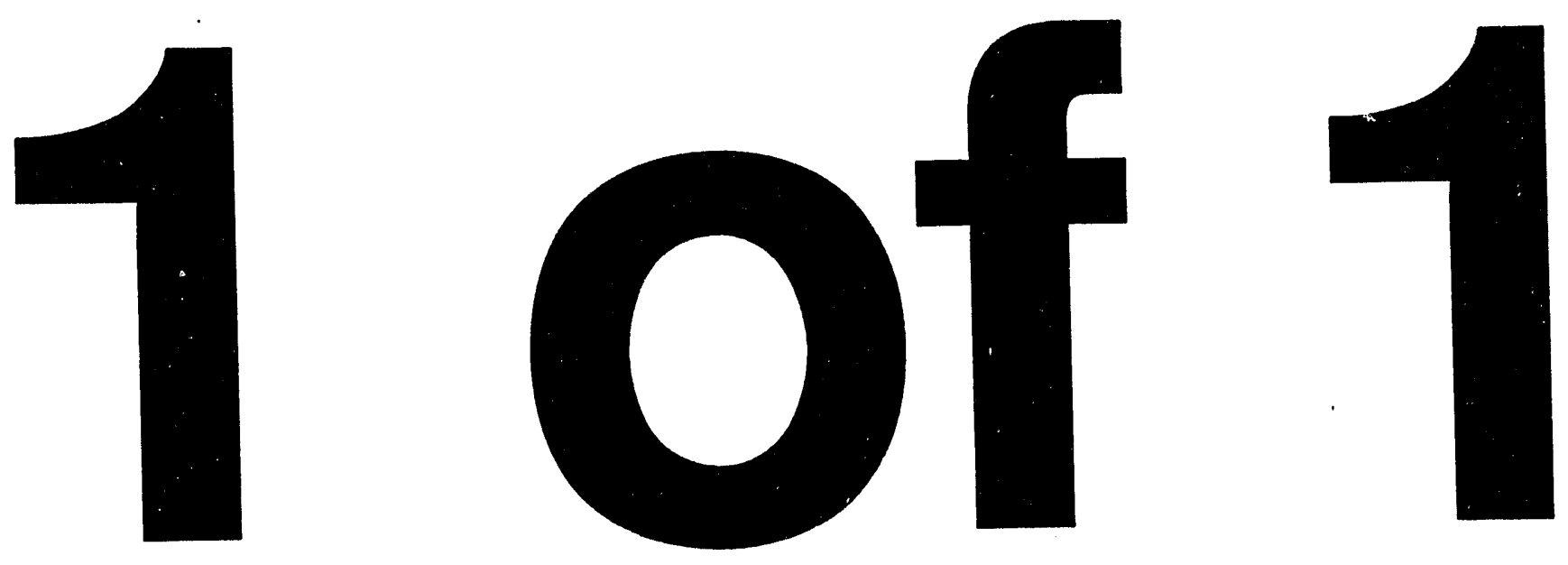
TITLE: MUSIC for Localization of Thunderstorm Ce11s

AUTHOR(S): John C. Mosher, Timothy M. Rynne, and Paul S. Lewis

submitTED TO: Proceedings Twenty-Seventh Annual Asilomar Conference on Signa1s, Systems, and Computers

Pacific Grove, CA.

November $1-3,1993$

\section{DISCLAIMER}

This report was prepared as an account of work sponsored by an agency of the United States Government. Neither the United States Government nor any agency thereof, nor any of their employees, makes any warranty, express or implied, or assumes any legal liability or responsibility for the accuracy, completeness, or usefulness of any information, apparatus, product, or process disclosed, or represents that its use would not infringe privately owned rights. Reference herein to any specific commercial product, process, or service by trade name, trademark, manufacturer, or otherwise does not necessarily constitute or imply its endorsement, recommendation, or favoring by the United States Government or any agency thereof. The views and opinions of authors expressed herein do not necessarily state or reflect those of the United States Government or any agency thereof.

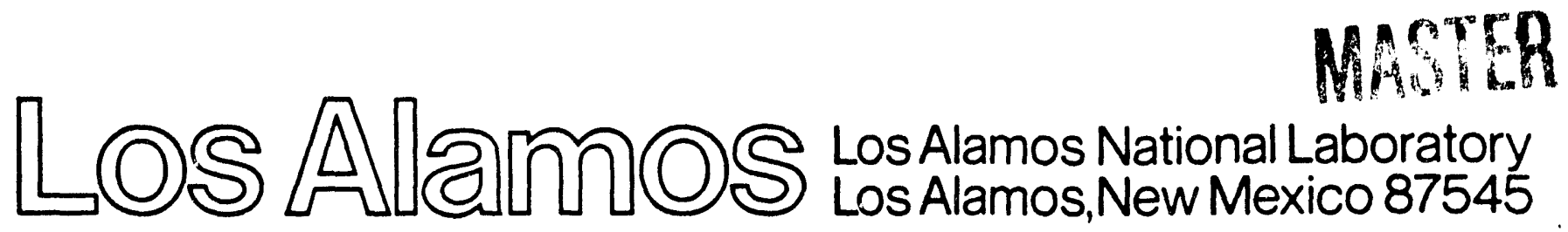




\title{
MUSIC for Localization of Thunderstorm Cells
}

\author{
John C. Mosher*, Timothy M. Rynne+, and Paul S. Lewis* \\ *Los Alamos National Laboratory \\ Group ESA-6, MS J580 \\ Los Alamos, NM 87545 USA \\ ${ }^{+}$Scientific Applications \& Research Associates, Inc. \\ PO Box 1758 \\ Huntington Beach, CA 92647-1758 USA
}

email: mosher@LANL.GOV

\begin{abstract}
Lightning represents an event detectable optically, electrically, and acoustically, and several systems are already in place to monitor such activity. Unfortunately, such detection of lightning can occur too late, since operations need to be protected in advance of the first lightning strike. Additionally, the bolt itself can traverse several kilometers before striking the ground, leaving a large region of uncertainty as to the center of the storm and its possible strike regions. NASA Kennedy Space Center has in place an array of electric field mills that monitor the (effectively) $D C$ electric field. Prior to the first lightning strike, the surface electric fields rise as the storm generator within a thundercloud begins charging. Extending methods we developed for an analogous source localization problem in magnetoencephalography, we present Cramer-Rao lower bounds and MUSIC scans for fitting a point-charge source model to the electric field mill data. Such techniques can allow for the identification and localization of charge centers in cloud structures.
\end{abstract}

\subsection{Introduction}

Lightning represents an event detectable optically, electrically, and acoustically, and several systems are already in place to monitor such activity. Unfortunately, such detection of a lightning event can occur too late, since many outdoor operations need to be protected before the lightning strikes. Additionally, the bolt itself can traverse several kilometers before striking the ground, leaving a large region of uncertainty as to the center of the storm and its possible strike regions. NASA Kennedy Space Center (KSC) and sites in New Mexico (two of the United States most active thunderstorm regions) have in place arrays of electric field mill sensors that monitor the (effectively) DC electric field. Prior to the first lightning strike, the surface electric fields rise dramatically as the storm generator within a thundercloud begins charging. Surface contours generated from these arrays can give indications of the

Los Alamos National Laboratory is operated by the University of California for the United States Department of Energy under contract W-7405-ENG-36. storm centers, but interpretation in real-time by operations personnel can be difficult. For example, NASA's operational guidelines are simply to halt activities if any contour line breaks $1000 \mathrm{Volts} / \mathrm{meter}$. However, non-threatening conditions such as ground fog and sea spray can also generate such fields, and operations are needlessly halted.

There is a pressing need for new analysis techniques for efficient and effective interpretation of this quasi-static electric field signal. We have been developing just such techniques for an analogous problem of source localization in human brain responses from the magnetoencephalogram (MEG) [1]. These MEG techniques are based on an adaptation of MUSIC, an algorithm originally developed for RF direction finding [2]. We have adapted this MEG research to the thunderstorm localization problem and applied our technique to data from the KSC field mill array.

\subsection{Background}

Figure 1 displays a photograph of one of the older field mills in use at KSC. KSC has begun a program to replace these older field mills with a more modern version, but the physical measurement concept remains the same. A spinning metal rotor alternatingly exposes and covers stationary metal plates (the spinning blade "mills" the field). Charges alternatingly accumulate in either the stator or rotor plates, and the sensor monitors the charge movement, which is proportional to the electric field. This older version transmitted the signal over analog land-lines to a central digitizing site; the modern mills digitize at the sensor before transmission over land-lines. Figure 2 shows the positions of the 31 field mills spread throughout the Cape Canaveral area.

The data received at the 31 electric field mills are formed into a spatiotemporal data matrix. Figure 3 displays the response of two selected mills over a time interval spanning the approach and then decline of a thunderstorm. Figure 4 displays the overlay of all mills in this same interval, a period of about four hours. Some of the key features in a thunderstorm are the onset of electrification, lightning activity, then end of storm oscillations (EOSO), during 


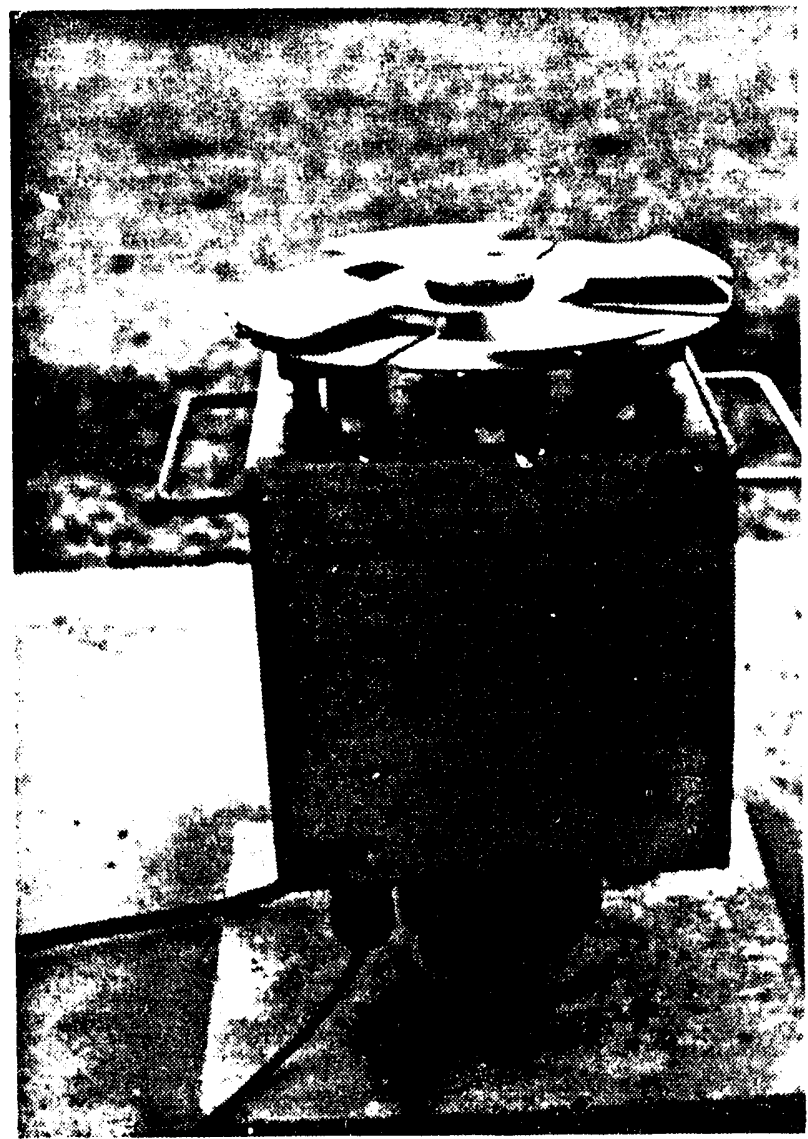

FIGURE 1 Electric Field Mill This older model is being upgraded to an inverted veision which better shelds the sensor from environmental conditions

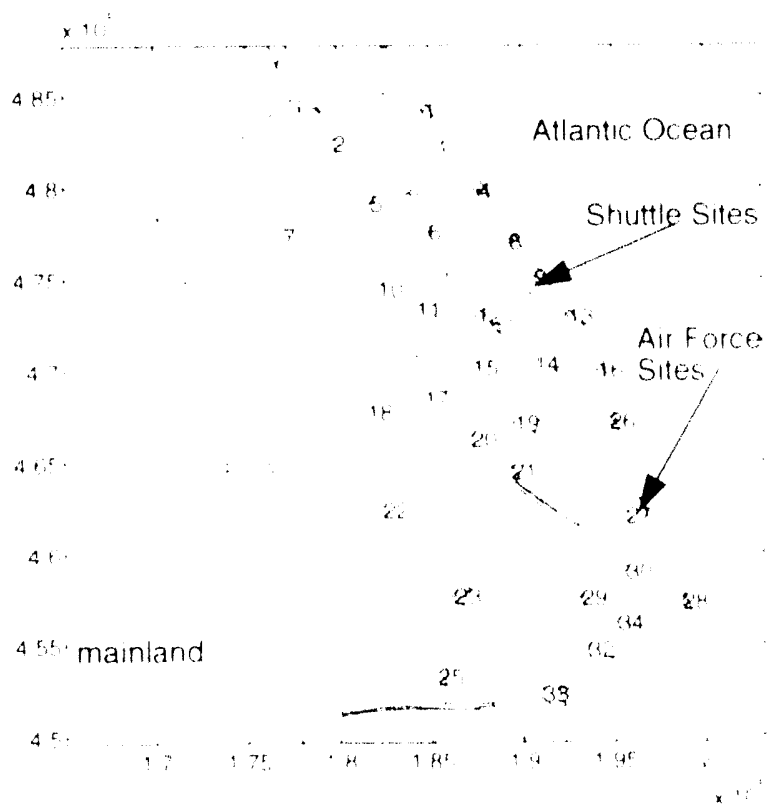

FIGURE 2 Locations of field mils throughout the Cape Canaveral area. The 31 sensors are numbered from 1 to 34. with some sensor numbers retred

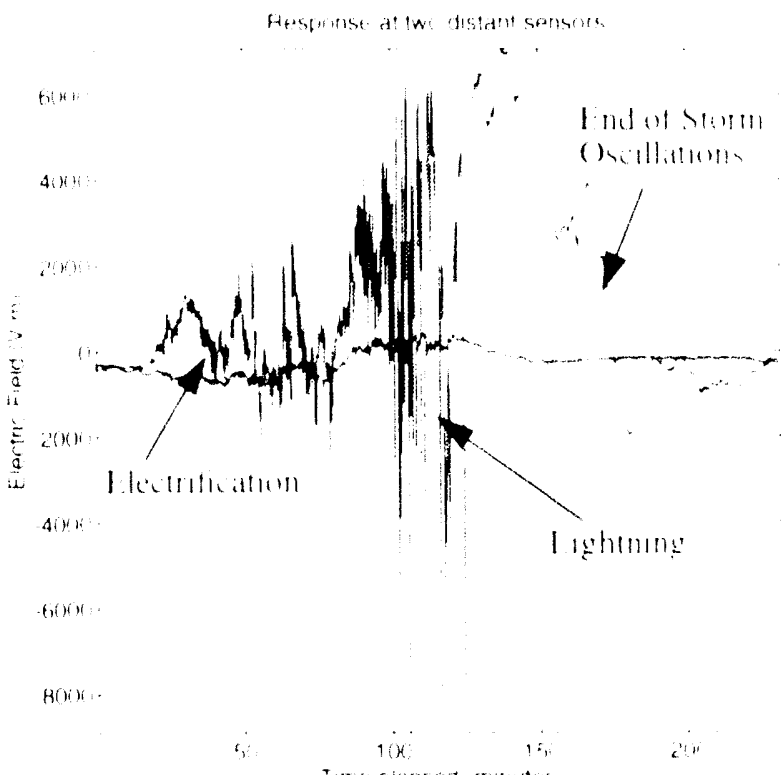

FIG JRE 3. Two selected responses of field mill sensors to thunderstorm activity. The larger response is from a sensor adjacent a storm cell the smaller response was from a sensof roughly $15 \mathrm{~km}$ distant

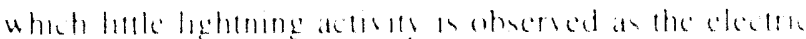

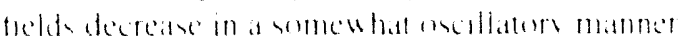

\subsection{Cramer-Rao l ower Bounds}

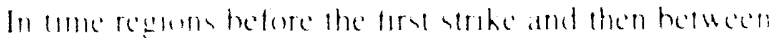

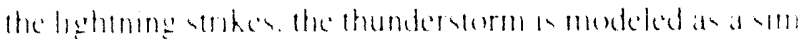

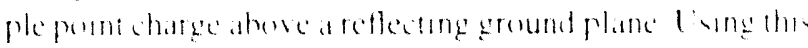

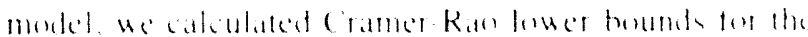

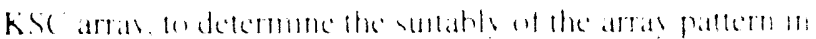

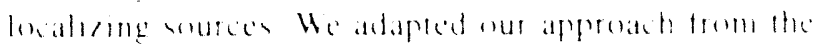

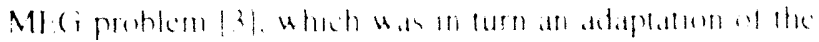
Wuth of $|4|$

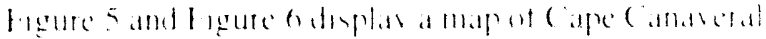

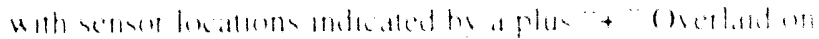

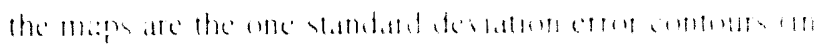

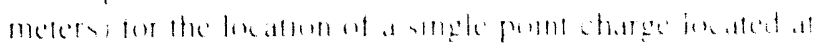

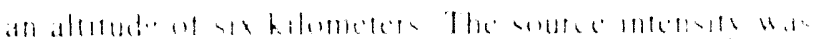

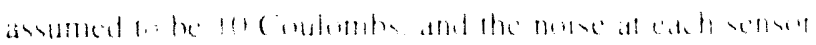

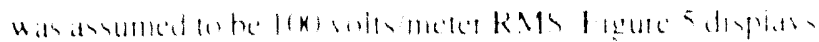

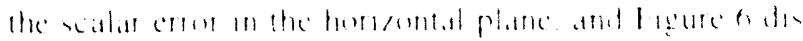

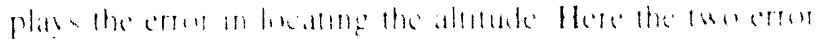

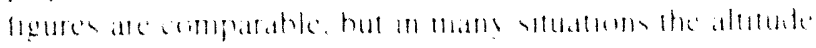

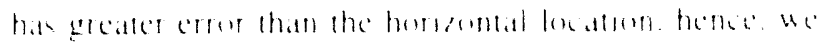

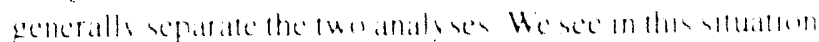

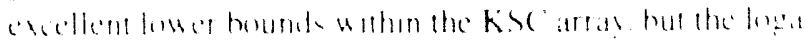

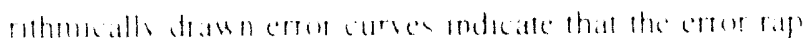

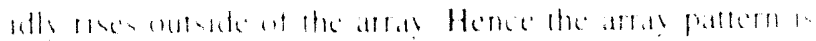

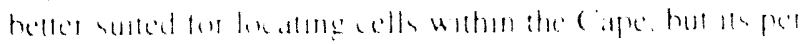

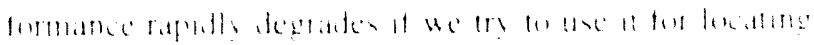

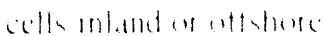




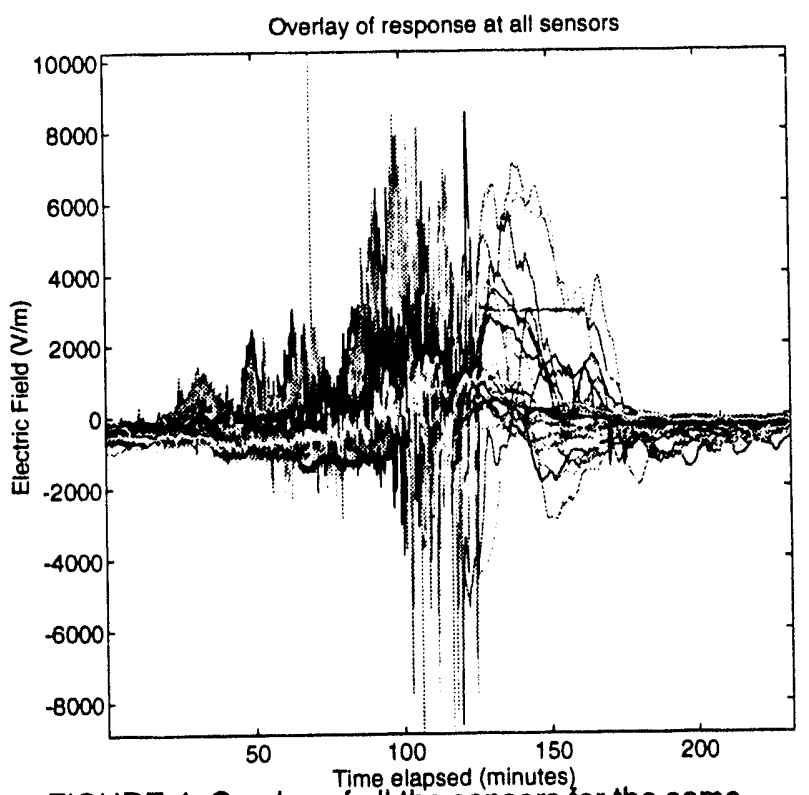

FIGURE 4. Overlay of all the sensors for the same storm observed in Figure 3.

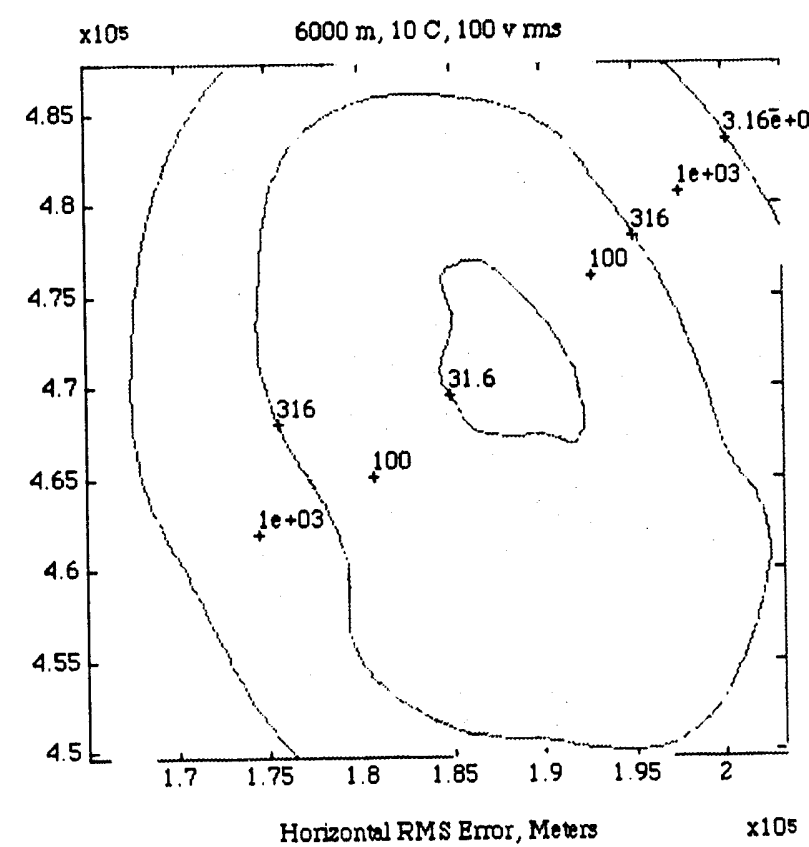

FIGURE 5. Cramer-Rao bounds for the NASA Kennedy Space Center - Cape Canaveral Air Force Station sensor array of 31 electric field mills. Source is 10 Coulombs point-charge $6 \mathrm{~km}$ over the Cape, with 100 volts/meter RMS noise assumed at each sensor. This figure is the scalar horizontal error.

\subsection{Contour Generation}

The existing KSC technique for processing the field mill data is to model the observed fields with 31 point charges placed $6 \mathrm{~km}$ directly over each sensor, then solve for the

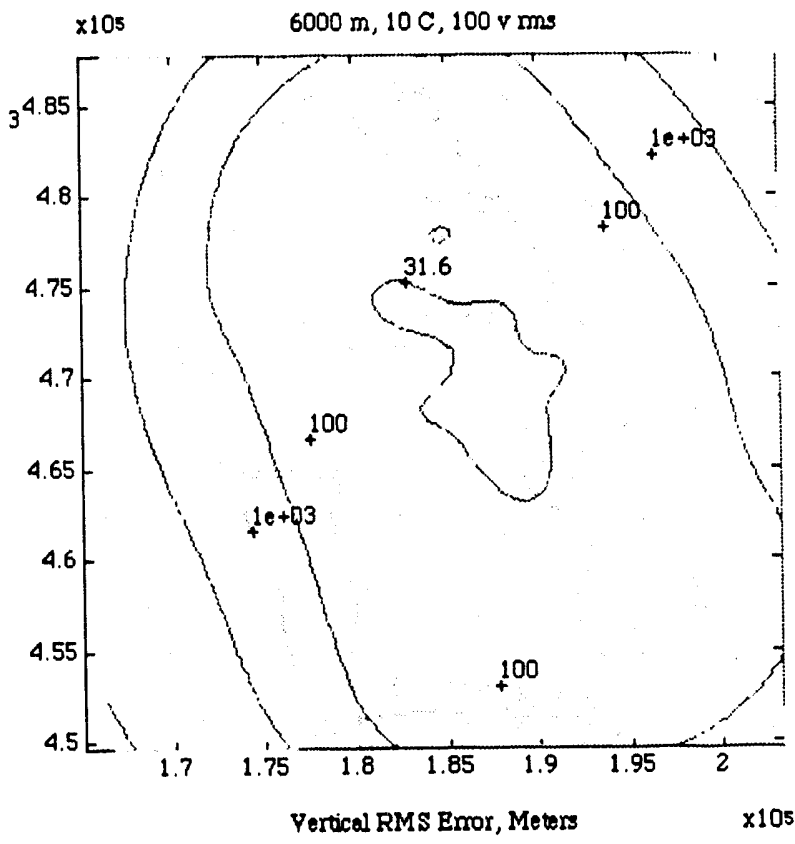

FIGURE 6. Error bounds for the altitude error. Contours are logarithmically drawn here and in Figure 5, and they represent the one standard deviation error bounds in meters.

unknown charges. These 31 charges form a relatively wellbehaved exactly constrained system of 31 equations. Once the inverse is found, these 31 solutions are then used in a forward calculation over a regular grid projected onto the Cape surface, in order to effectively estimate the fields everywhere at the Earth's surface. This estimation is then used to generate contour lines on the earth's surface.

This model has the benefit that the total transformational matrix can be calculated once off-line, then applied easily in real-time as data "snapshots" from the array become available; however, this model does suffer from sensitivities to relatively small perturbations in some sensors. Additionally, some of the apparent field patterns can appear quite contrived, apparently indicating multiple storm sources that do not coincide with other expert knowledge and modalities, such as weather radar. This model, however, has been in use for two decades at KSC, and a heuristic interpretation of its output has been acquired by KSC personnel. Thus this method of contour generation will be used as a comparison test against the Thunderstorm MUSIC.

\subsection{Thunderstorm MUSIC}

The sensors are recording a quasi-static electric field signal, so no time-of-arrival information among sensors is available. As in the MEG problem, we instead exploit the near-field intensity of the signal and the signal's assumed 


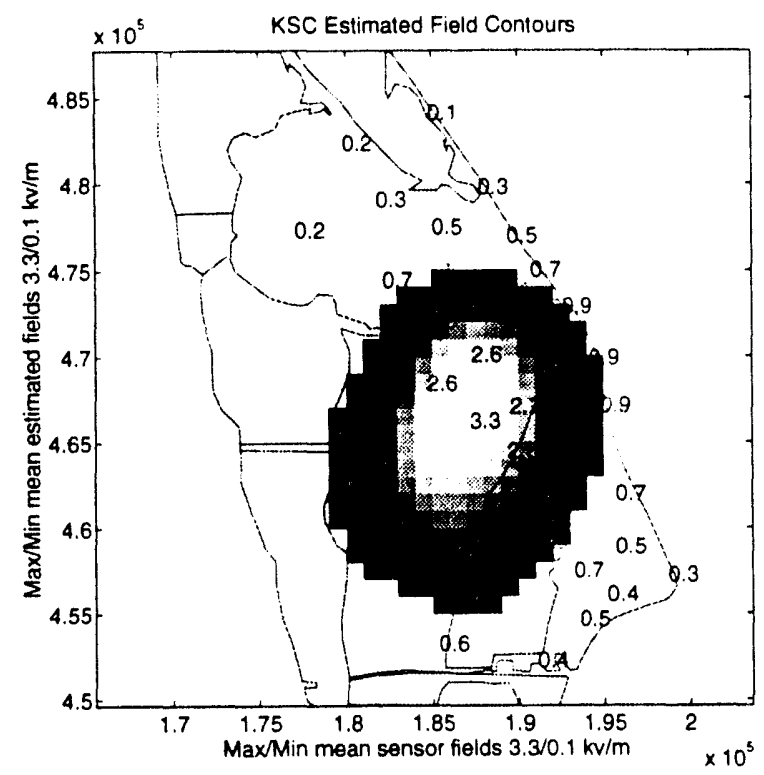

FIGURE 7. Contour generation from KSC Model for two simulated sources. Compare with Figure 8.

algebraic independence from other sources. The matrix is decomposed into signal and noise subspaces through conventional eigendecomposition approaches. An array manifold is formed for the point charge model over a conducting plane and scanned in three dimensions through the signal subspace, looking for intersections of the model and data spaces. The metric recorded at each point is the primary cosine of the angle between the model and signal subspace, such that unity indicates a perfect intersection of the primary vectors [5]. The observed rank of the signal subspace is typically less than 5 .

In spite of this oversimplification of the thunderstorm model, the point-charge results are quite promising. We present a simulation and a data example to illustrate the potential of the thunderstorm MUSIC in processing KSC field mill data. Figure 7 and Figure 8 present the KSC contour model and the results of a MUSIC scan for a two source equal intensity simulation. The contours were generated from the average observed field, while the MUSIC image was generated from a rank 2 analysis of the same interval. Only the field values above $1 \mathrm{kv} / \mathrm{m}$ were imaged in the KSC model, while only MUSIC peaks above 0.9 were imaged. We see that the MUSIC scan correctly identifies the two peaks, while the KSC model results in an overall blur.

Figure 9 displays a 200 second time interval during a thunderstorm recorded on August 5, 1991, during the CAPE program. The arrow indicates the region analyzed by both the KSC model and the Thunderstorm MUSIC. Figure 10 displays the contours from the KSC model, and Figure 11 displays the MUSIC image. The two results now disagree in the apparent location of the storm cell; however,

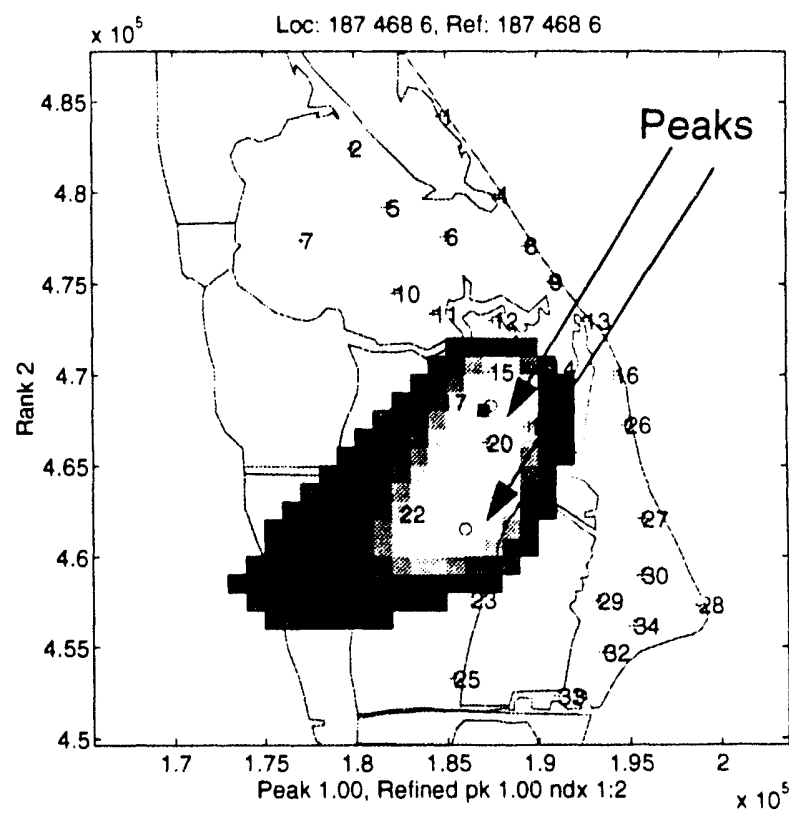

FIGURE 8. MUSIC images for two source simulation. Peaks occur at proper locations.

the KSC model was observed to have a large variability in the apparent peak of the field as a function of time, while the MUSIC peak was relatively stationary. The MUSIC peak of 0.98 indicates a very good fit between the model and the rank 5 subspace. Unfortunately, "ground truth" is not readily available for this data set, and future efforts will focus on data sets where other corroborating modalities are available, such as weather radar and lightning detection systems.

\section{References}

[1] Mosher JC, Lewis PS, and Leahy RM, "Multiple dipole modeling and jocalization from spatio-temporal MEG data," IEEE Trans. Biomedical Eng, 1992, 39:541-557.

[2] Schmidt RO. "Multiple emitter location and signal parameter estimation," IEEE Transactions on Antennas and Propagation, vol. AP-34, pp. 276-280, March 1986. Reprint of the original 1979 paper from the RADC Spectrum Estimation Workshop.

[3] Mosher JC, Spencer ME, Leahy RM, Lewis PS, "Error bounds for EEG and MEG dipole source localization." Electroenceph. and clin. Neurophys, 1993, 86:303-321.

[4] Stoica P and Nehorai A, "MUSIC, maximum likelihood, and Cramer-Rao bound," IEEE Transactions on Acoustics, Speech and Signal Processing, vol. 37, pp. 720-741. May 1989.

[5] Golub GH and Loan CFV, Matrix Computations. Baltimore, MD: The Johns Hopkins University Press, second ed., 1989. 


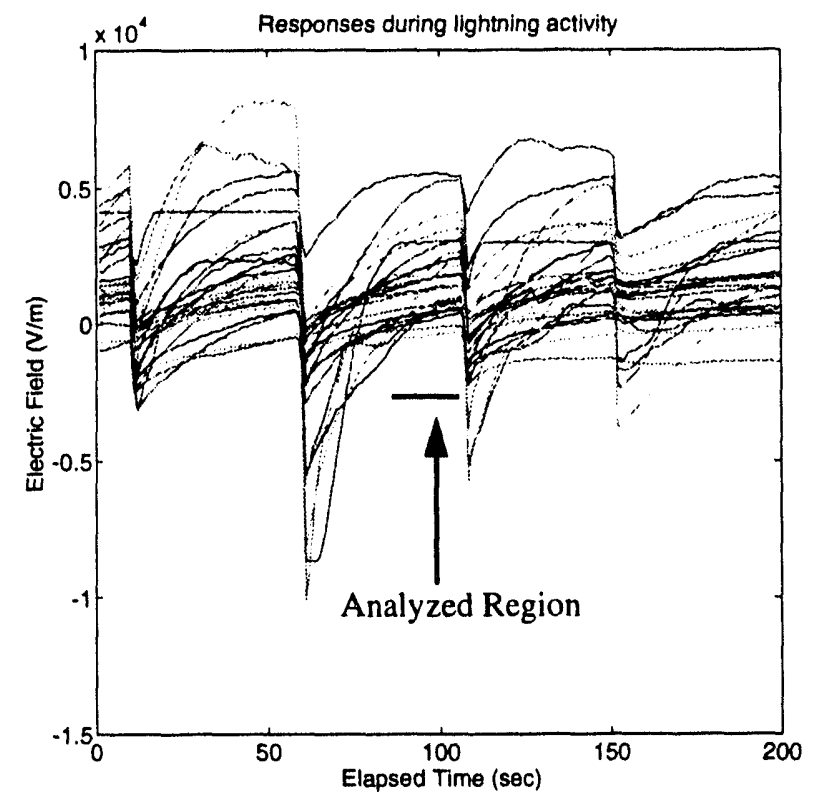

FIGURE 9. Overlay of sensor responses during 200 seconds of thunderstorm activity. Sharp changes are the response of the mills to lightning activity. The data are analyzed just prior to a lightning strike. Some other features to note are the apparent exponential clamping of the fields (a physical phenomenon), as well as some clipped sensor responses (a sensor problem).

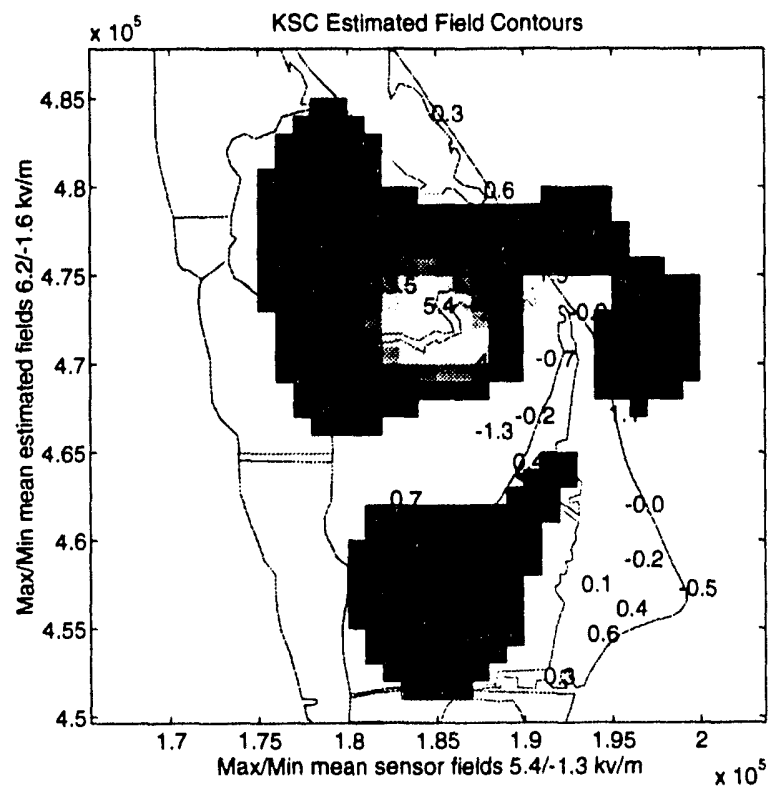

FIGURE 10. Estimated fields using KSC model for the data in Figure 9 . Only fields above $1 \mathrm{kv} / \mathrm{m}$ were imaged. Compare with Figure 11

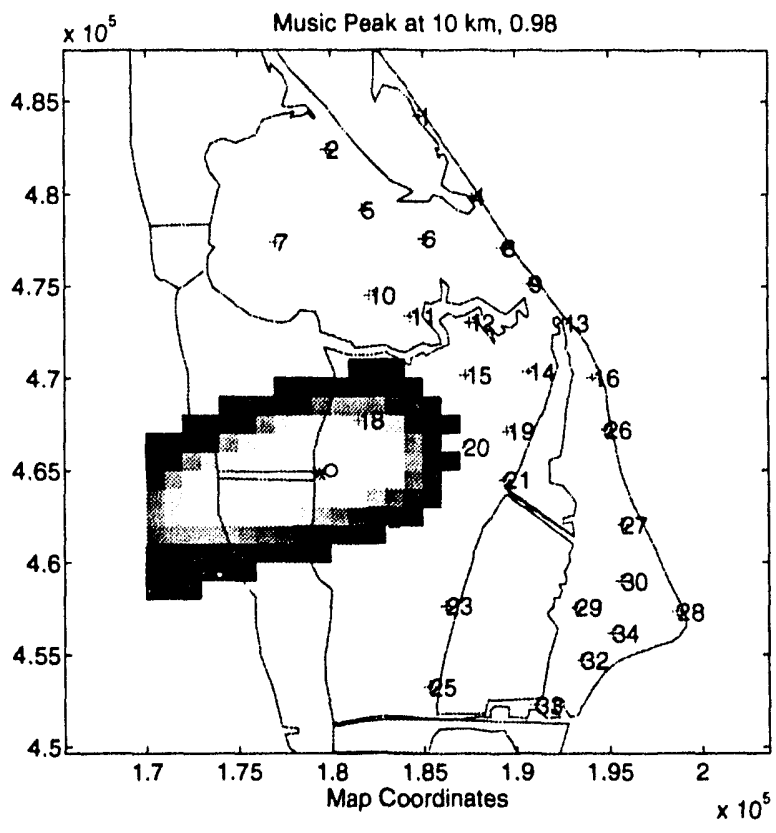

FIGURE 11. MUSIC Image for same period. This location was consistently found over many time intervals, unlike the estimated field peak in Figure 10; 

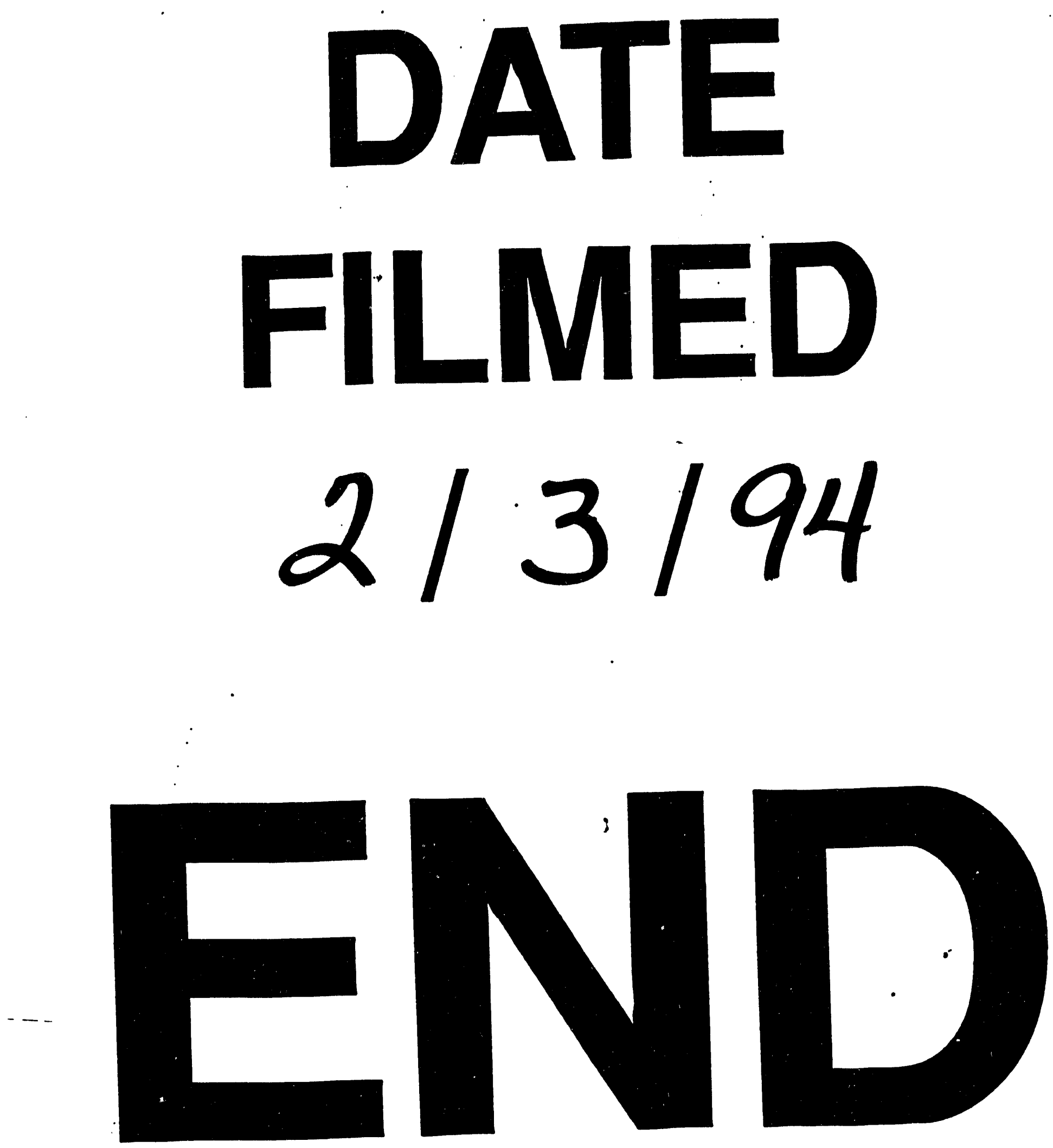
